\title{
On Respiratory Rate of Cherry Tomatoes under Subcritical Heights
}

\author{
Fang Duan,, Yu-fen Chen, ${ }^{2}$ Zhong-zheng Sun, ${ }^{2}$ Ming-qing Chen, \\ Hui Zhang, ${ }^{3}$ and Jing Zhang ${ }^{3}$ \\ ${ }^{1}$ Department of Materials Engineering, Jiangnan University, Wuxi 214122, China \\ ${ }^{2}$ School of Mechanical Engineering, Jiangnan University, Wuxi 214122, China \\ ${ }^{3}$ Jiangyin Propack Packing Co., Ltd., Jiangyin 214433, China \\ Correspondence should be addressed to Ming-qing Chen; mqsytu1@126.com
}

Received 12 May 2013; Accepted 12 June 2013

Academic Editor: Jun Wang

Copyright (C) 2013 Fang Duan et al. This is an open access article distributed under the Creative Commons Attribution License, which permits unrestricted use, distribution, and reproduction in any medium, provided the original work is properly cited.

\begin{abstract}
The influence of subcritical drop heights on respiratory rate was studied for cherry tomatoes. The cherry tomatoes were dropped, and the mean value of $\mathrm{O}_{2}$ concentration was measured, and then the respiration rate was calculated. The results showed that the respiration rate of the cherry tomatoes increases remarkably with the dropping height. Finally, the relationship between the subcritical dropping heights and respiration rate was modeled and validated, showing good agreement.
\end{abstract}

\section{Introduction}

Respiration of fruits and vegetables is an important physiological activity in the postharvest and also is an important factor affecting the storage lifetime, but one of major factors affecting the respiration of picked fruits is the mechanical damage $[1,2]$. Fruits may suffer the damage of varying degrees during harvest, classification, packaging, transportation, loading and unloading, and storage, which will lead to the change in the respiration rate, the decline in quality, and the decrease in the storage time. Therefore, studying and forecasting the fruits breathing intensity not only are essential for the fruits' storage and preservation but also have directive significance to the fruits' packaging design. Domestic and foreign scholars have conducted many related researches. Chen Shoujiang and Dejing [3] studied the effect of mechanical stress by falling from different height on senescence of the strawberry during cold storage. The results showed that each index of strawberry fruit decreased with the increase of mechanical damage. Lin et al. [4] studied the influence of mechanical stress on the active oxygen metabolism system of apple during transportation. Lixin and Zhiwei [5] performed the quasi-static compression testing with two kinds of pear specimens of full flesh and developed a general rheological model of a nonlinear visco elastic plastic solid. Van Zeebroeck et al. [6] simulated fruit impact damage during transport and handling. Reinosuke et al. [7, 8] studied the changes in respiration rate of several fruits during and after vibration. Brusewitz and Bartsch [9] studied the impact parameters related to postharvest brusing of apples. Parks [10] studied sugarbeet injury within harvesting and handling equipment and used many ways to evaluate sugarbeet, including measuring respiration rate and the amount of sucrose and impurities in the root while in storage.

The harsh mechanical environment that the fruits may encounter in circulation is the drop impact on the ground, the dock, or the station. The dropping height is the direct strength parameter under the external mechanical stimulation. The respiration rate of the fruits while dropping is related not only with the mechanical damage but also with the temperature and humidity, the proportion of the air, and so on. The above studies are basically about the research of the changes in the nutrient and respiratory rate of fruits which have been destroyed, but there is no related study on the influence of sub-critical dropping heights (the heights below the critical dropping height) on the respiration rate of fruits and vegetables. The fruits will be damaged dropping from the height above the critical dropping height, but the effect of subcritical 
TABLE 1: Changes of cherry tomatoes' respiratory rate over time under different dropping heights.

\begin{tabular}{|c|c|c|c|c|c|c|c|c|c|c|}
\hline $\begin{array}{l}\text { Dropping } \\
\text { heights } / \mathrm{cm}\end{array}$ & & 0 & & 5 & & 10 & & 15 & & 20 \\
\hline Time/h & $C\left(\mathrm{O}_{2}\right) / \%$ & $\begin{array}{c}R\left(\mathrm{O}_{2}\right) / \mathrm{mL} / \\
(\mathrm{kg} \cdot \mathrm{h})\end{array}$ & $C\left(\mathrm{O}_{2}\right) / \%$ & $\begin{array}{c}R\left(\mathrm{O}_{2}\right) / \mathrm{mL} / \\
(\mathrm{kg} \cdot \mathrm{h})\end{array}$ & $C\left(\mathrm{O}_{2}\right) / \%$ & $\begin{array}{c}R\left(\mathrm{O}_{2}\right) / \mathrm{mL} / \\
(\mathrm{kg} \cdot \mathrm{h})\end{array}$ & $C\left(\mathrm{O}_{2}\right) / \%$ & $\begin{array}{c}R\left(\mathrm{O}_{2}\right) / \mathrm{mL} / \\
(\mathrm{kg} \cdot \mathrm{h})\end{array}$ & $C\left(\mathrm{O}_{2}\right) / \%$ & $\begin{array}{c}R\left(\mathrm{O}_{2}\right) / \mathrm{mL} / \\
(\mathrm{kg} \cdot \mathrm{h})\end{array}$ \\
\hline 0 & 20.0 & I & 20.0 & I & 20.0 & I & 20.0 & I & 20.0 & I \\
\hline 1 & 19.7 & 30.0 & 19.7 & 30.0 & 19.7 & 30.0 & 19.7 & 30.0 & 19.7 & 30.0 \\
\hline 3 & 19.2 & 25.0 & 19.2 & 25.0 & 19.2 & 25.0 & 19.2 & 25.0 & 19.3 & 20.0 \\
\hline 6 & 18.6 & 20.0 & 18.7 & 16.7 & 18.7 & 16.7 & 18.8 & 13.3 & 18.8 & 16.7 \\
\hline 12 & 18.0 & 10.0 & 18.1 & 10.0 & 18.0 & 11.7 & 18.0 & 13.3 & 17.9 & 15.0 \\
\hline 24 & 17.0 & 8.3 & 17.0 & 9.2 & 17.0 & 8.3 & 16.9 & 9.2 & 16.7 & 10.0 \\
\hline 36 & 16.1 & 7.5 & 16.0 & 8.3 & 16.1 & 7.5 & 15.9 & 8.3 & 15.6 & 9.2 \\
\hline 60 & 14.8 & 5.4 & 14.6 & 5.8 & 14.8 & 5.4 & 14.4 & 6.3 & 14.0 & 6.7 \\
\hline 84 & 13.6 & 5.0 & 13.4 & 5.0 & 13.5 & 5.4 & 13.0 & 5.8 & 12.5 & 6.3 \\
\hline 108 & 12.5 & 4.6 & 12.4 & 4.2 & 12.5 & 4.2 & 11.6 & 5.8 & 11.0 & 6.3 \\
\hline 132 & 11.5 & 4.2 & 11.4 & 4.2 & 11.5 & 4.2 & 10.2 & 5.8 & 9.5 & 6.3 \\
\hline 156 & 10.6 & 3.8 & 10.4 & 4.2 & 10.5 & 4.2 & 8.8 & 5.8 & 8 & 6.3 \\
\hline 180 & 9.7 & 3.8 & 9.4 & 4.2 & 9.5 & 4.2 & 7.4 & 5.8 & 6.5 & 6.3 \\
\hline
\end{tabular}

dropping height on the respiration rate of fruits is still unknown. It is desirable to obtain the relationship between the subcritical dropping height and the respiration rate for fruits. In this paper, the respiration rate of cherry tomatoes under different subcritical dropping heights is studied, and a mathematical model is developed, acquiring the relationship between the dropping height and respiratory rate.

\section{The Measuring of Respiratory Rate}

2.1. Test Materials. We used cherry tomatoes of an equal weight, which is about $100 \mathrm{~g} \pm 0.5 \mathrm{~g}$.

2.2. Test Method. Divide the cherry tomatoes into three groups, make sure the weight of 3 small experimental groups in each group is equal, and number each experimental group as 1-a, 1-b, 1-c, 2-a, 2-b, 2-c.... Determine three subcritical heights as $5 \mathrm{~cm}, 10 \mathrm{~cm}$, and $15 \mathrm{~cm}$, dropping, respectively, at the height of $5 \mathrm{~cm}, 10 \mathrm{~cm}, 15 \mathrm{~cm}$, and $20 \mathrm{~cm}$ using the selfmade dropping device, then put them in the crisper for sealing, and then test $\mathrm{O}_{2} / \mathrm{CO}_{2}$ concentration of each test group within the crisper at a specific interval time $(1 \mathrm{~h}, 2 \mathrm{~h}, 3 \mathrm{~h}$, $6 \mathrm{~h}, 12 \mathrm{~h}, 12 \mathrm{~h}, 24 \mathrm{~h}, 24 \mathrm{~h}, 24 \mathrm{~h}, 24 \mathrm{~h}, 24 \mathrm{~h}$, and $24 \mathrm{~h}$ ). In order to minimize the error caused by the instrument extracting gas, each experimental group also includes three crispers, so different crisper is tested in each measurement. Record and analysis the test data, and then calculate the respiration rate of cherry tomatoes at different dropping heights, and finally analyze the relationship between the two.

2.3. Test Instrument. Plastic sealed box $(1000 \mathrm{~mL})$, the top air analyzer of $\mathrm{O}_{2} / \mathrm{CO}_{2}$, the laboratory-made dropping device, and the silicone gasket were used.

2.4. Test Result and Discussion. Measure the mean value of $\mathrm{O}_{2}$ concentration of the cherry tomatoes at the different

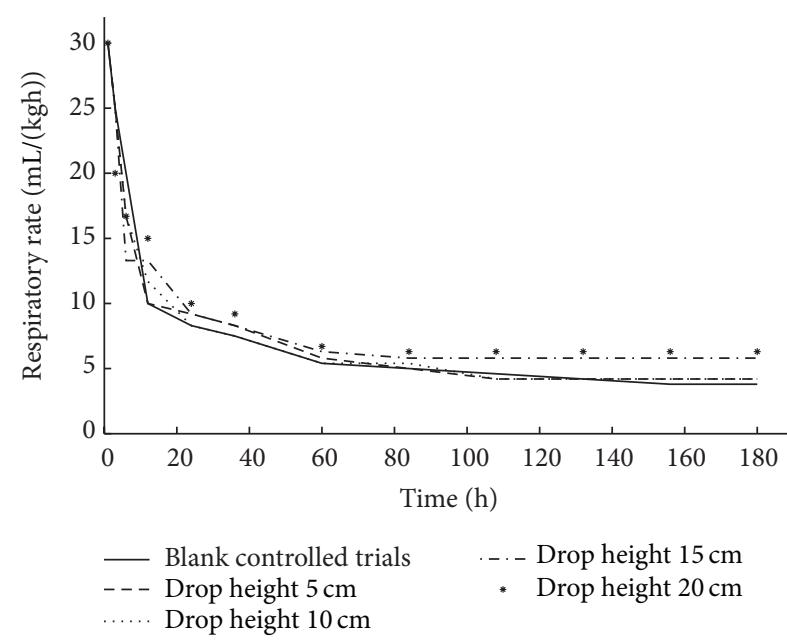

FIGURE 1: Effect of different sub-critical dropping heights on cherry tomatoes' respiratory rate.

dropping heights, and calculate the respiration rate $R\left(\mathrm{O}_{2}\right)$ according to (1), as shown in Table 1:

$$
R_{\mathrm{O}_{2}}=\frac{\left(C_{\mathrm{O}_{2}}^{t_{i}}-C_{\mathrm{O}_{2}}^{t_{f}}\right) \times V}{100 \times M \times\left(t_{f}-t_{i}\right)},
$$

where $t_{i}$ and $t_{f}$ denote, respectively, the starting and terminal testing time. $C_{\mathrm{O}_{2}}^{t_{i}}$ and $C_{\mathrm{O}_{2}}^{t_{f}}$ represent the concentration of $\mathrm{O}_{2}$. $V$ is the free volume of the container, and $M$ is the mass of fruit.

With the $\mathrm{O}_{2}$ concentration of the cherry tomatoes at the different dropping heights, the respiration rate $R\left(\mathrm{O}_{2}\right)$ calculated according to (1) was obtained and compared for different sub-critical dropping heights, as shown in Figure 1. 


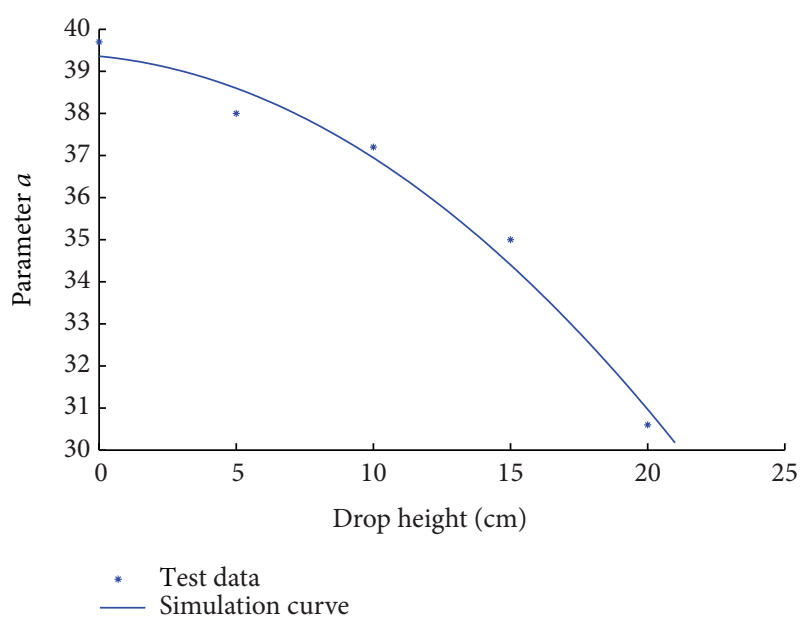

Figure 2: $a$ - $h$ Simulation curve.

The following conclusions can be obtained through the above chart. The respiration rate of the cherry tomatoes decreases with the increase of the storage time, finally moves towards balance, and significantly decreases in the beginning, and the more the dropping heights the more obviously the downward trend, and it shortens the time of reaching the state of equilibrium. In addition, the more the dropping heights, the increaser the respiration rate of the the cherry tomatoes.

\section{Mathematical Model and Characterization of the Relationship between Subcritical Load Intensity and Respiration Intensity}

According to the dependence nature of cherry tomatoes' respiratory rate on sub-critical dropping height, it is possible to model the relationship between the dropping height and the respiration rate. Firstly, the time-dependent respiratory rate meets the following general formula $[11,12]$ :

$$
R\left(\mathrm{O}_{2}\right)=a t^{-0.25}+b
$$

Then, the relationship between the dropping height and the model parameter $a$ and $b$ were fitted, respectively. From Figures 2 and 3 , the fitting models for $a$ and $b$ with the dropping height can be obtained:

$$
\begin{gathered}
a=-0.01783 h^{2}-0.06303 h+39.36 \\
b=0.001101 h^{3}-0.01897 h^{2}+0.259 h-8.094 .
\end{gathered}
$$

Finally, substituting (3) into (2), the mathematical model of the relationship between the subcritical load intensity and the respiration intensity is obtained:

$$
\begin{aligned}
R\left(\mathrm{O}_{2}\right)= & \left(-0.01783 h^{2}-0.06303 h+39.36\right) t^{-0.25} \\
& +\left(0.001101 h^{3}-0.01897 h^{2}+0.259 h-8.094\right) .
\end{aligned}
$$

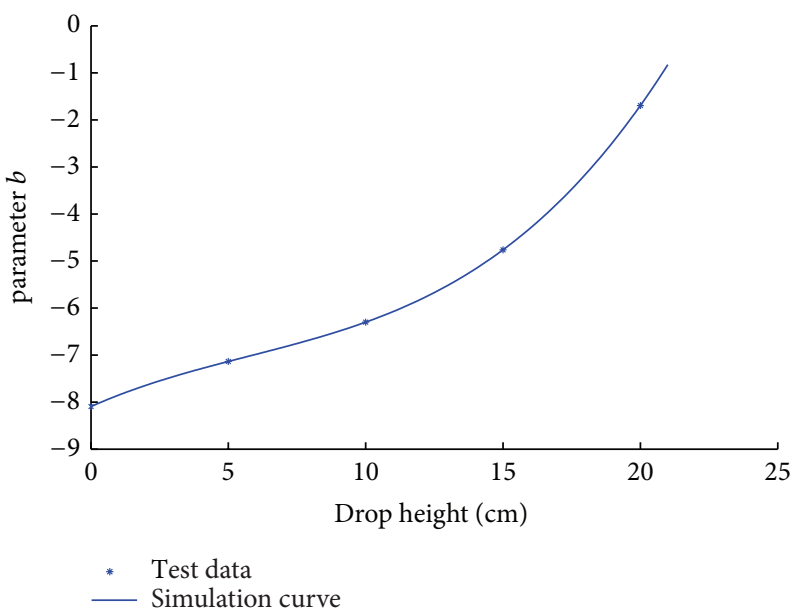

FIGURE 3: $b$ - $h$ Simulation curve.

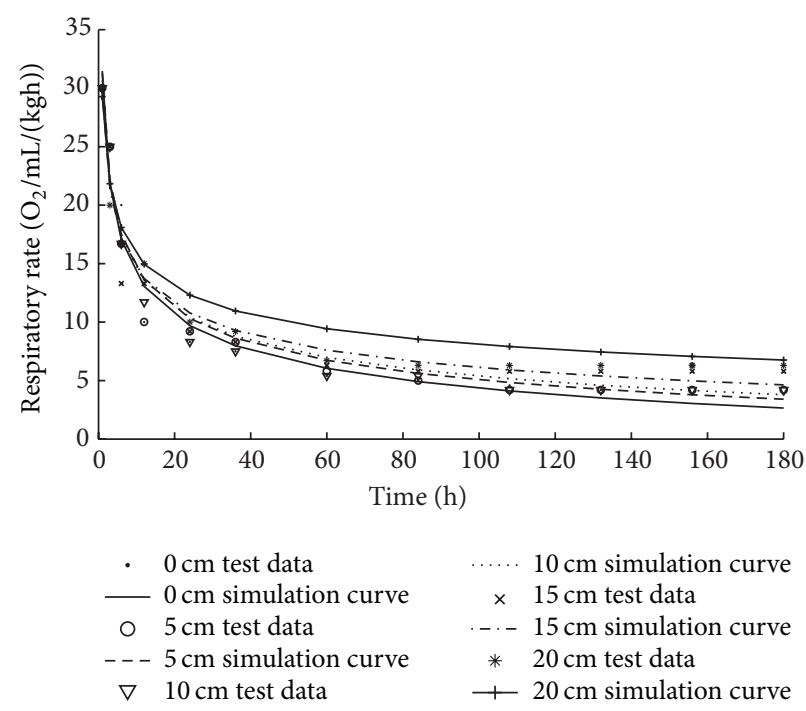

FIGURE 4: Comparison of the simulation curve and test data for respiratory rate under different dropping heights.

To validate the model proposed, the experiment results are compared with model for different dropping heights, as shown in Figure 4, showing good agreement.

\section{Conclusion}

In this paper, the respiration intensity of the cherry tomatoes is determined at different subcritical dropping heights, and a mathematical model of the relationship between the respiration rate and the dropping height is developed. The cherry tomatoes were dropped, and the mean value of $\mathrm{O}_{2}$ concentration was measured, and then the respiration rate was calculated. The results showed that the respiration rate of the cherry tomatoes increases remarkably with the dropping height. Finally, the relationship between the sub-critical dropping heights and respiration rate was modeled and validated, showing good agreement. However, the respiration rate of 
the cherry tomatoes is related not only with the mechanical damage but also with the temperature and humidity, the proportion of the air, and so on. If a comprehensive understanding of the respiration rate of the cherry tomatoes is made, it is desirable to establish a mathematical model based on different factors. Only in this way it can provide a strong basis for the cherry tomatoes picking, storage, transportation, and sale.

\section{Authors' Contribution}

Chen Yu-fen and Duan Fang contribute equally to the paper as cofirst authors.

\section{References}

[1] Y. Tiejin, Storage and Transportation of Fruit and Vegetable, Zhejiang University Press, Hangzhou, China, 2001.

[2] L. Lixin, The Packaging of Fruit, Vegetable and Its Products, Chemical industry press, Hoboken, NJ, USA, 2005.

[3] C. Shoujiang and Z. Dejing, "The effect on strawberry' physiological during the period of storage after mechanical samage," Preservation and Processing, vol. 1, pp. 16-17, 2006.

[4] S. Lin, S. Jiping, and L. Yunbo, "The effects on reactive oxygen species metabolism of the early storage of apples after mechanical damage," Journal of China Agricultural University, vol. 5, pp. 107-110, 1999.

[5] L. Lixin and W. Zhiwei, "Nonlinear viscoelastic plastic model of the fruits under quasi-static compressive loading," Transactions of the Chinese Society of Agricultural Engineering, vol. 21, no. 12, pp. 30-33, 2005.

[6] M. van Zeebroeck, E. Tijskens, E. Dintwa et al., "The discrete element method (DEM) to simulate fruit impact damage during transport and handling: case study of vibration damage during apple bulk transport," Postharvest Biology and Technology, vol. 41, no. 1, pp. 92-100, 2006.

[7] N. Reinosuke, I. Takashi, and I. Takuji, "Changes in respiration rate of several fruits during and after vibration," Journal of Japan Society for Horticultural Science, vol. 54, no. 4, pp. 498-506, 1986.

[8] N. Reinosuke, I. Takashi, and I. Akitsugu, "The effort of vibration on the respiration of fruit II: effects of vibration on the respiration rate and the quality of tomato fruit during ripening after vibration," Journal of Japan Society For Horticultural Science, vol. 46, no. 3, pp. 349-360, 1977.

[9] G. H. Brusewitz and J. A. Bartsch, "Impact parameters related to post harves bruising of apples," Transactions of the American Society of Agricultural Engineers, vol. 32, no. 3, pp. 953-957, 1989.

[10] D. L. Parks and C. L. Peterson, "Sugarbeet injury within harvesting and handling equipment," Transactions of the ASAE, vol. 22, no. 6, pp. 1238-1244, 1972.

[11] Y. Makino, K. Iwasaki, and T. Hirata, "Oxygen consumption model for fresh produce on the basis of adsorption theory," Transactions of the American Society of Agricultural Engineers, vol. 39, no. 3, pp. 1067-1073, 1996.

[12] K. I. Segall and M. G. Scanlon, "Design and analysis of a modified-atmosphere package for minimally processed romaine lettuce," Journal of the American Society for Horticultural Science, vol. 121, no. 4, pp. 722-729, 1996. 


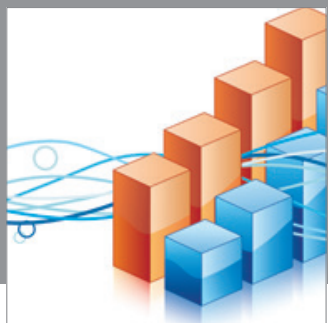

Advances in

Operations Research

mansans

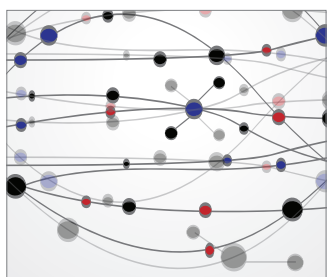

The Scientific World Journal
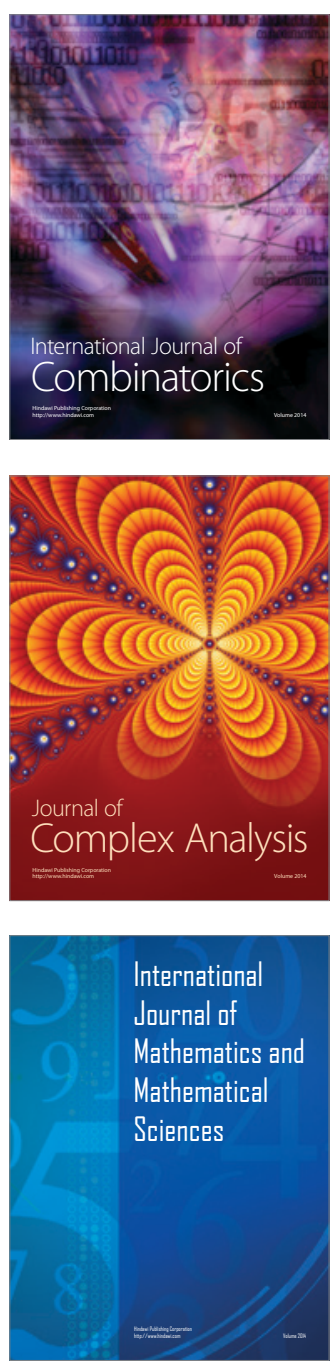
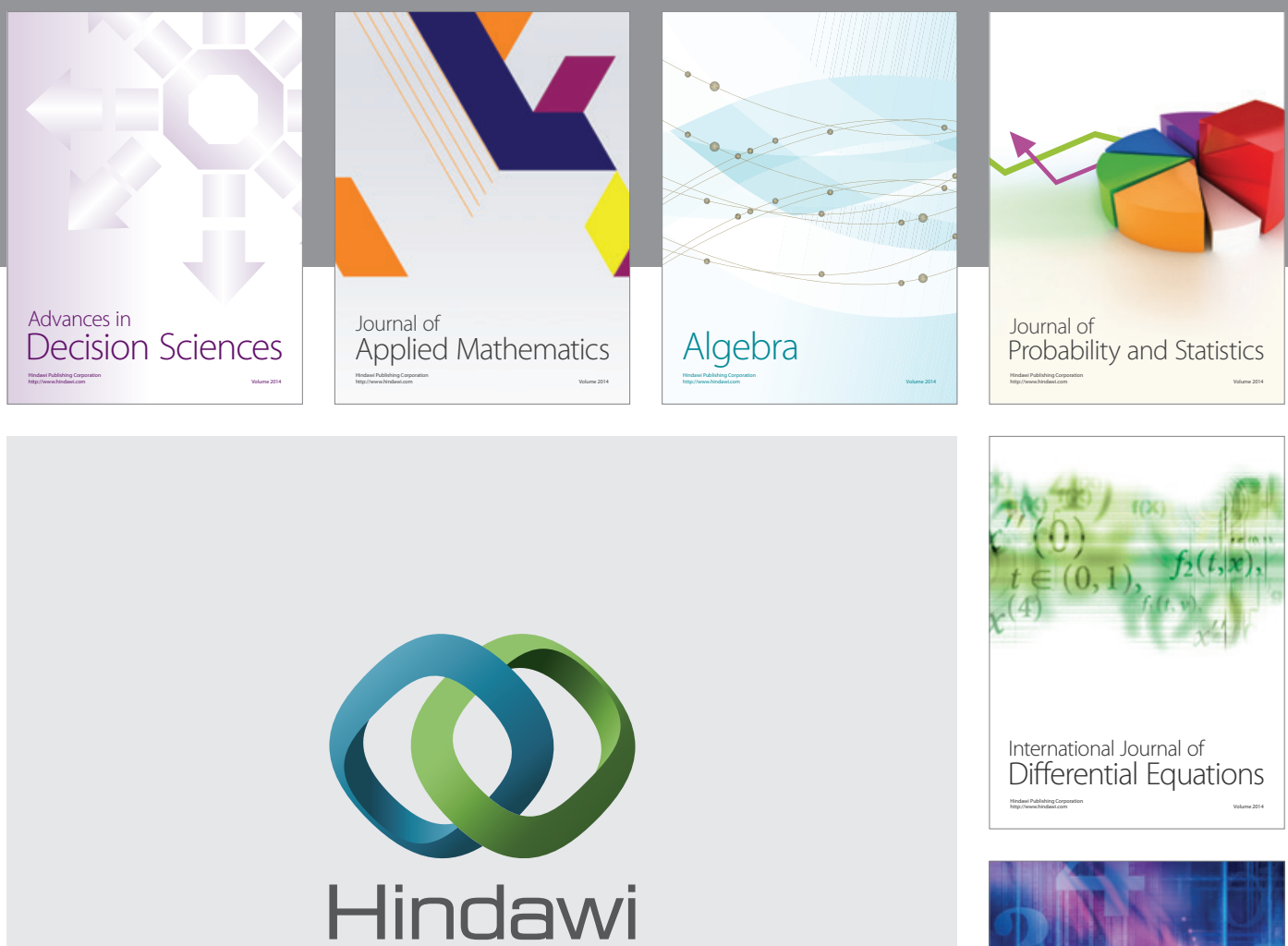

Submit your manuscripts at http://www.hindawi.com
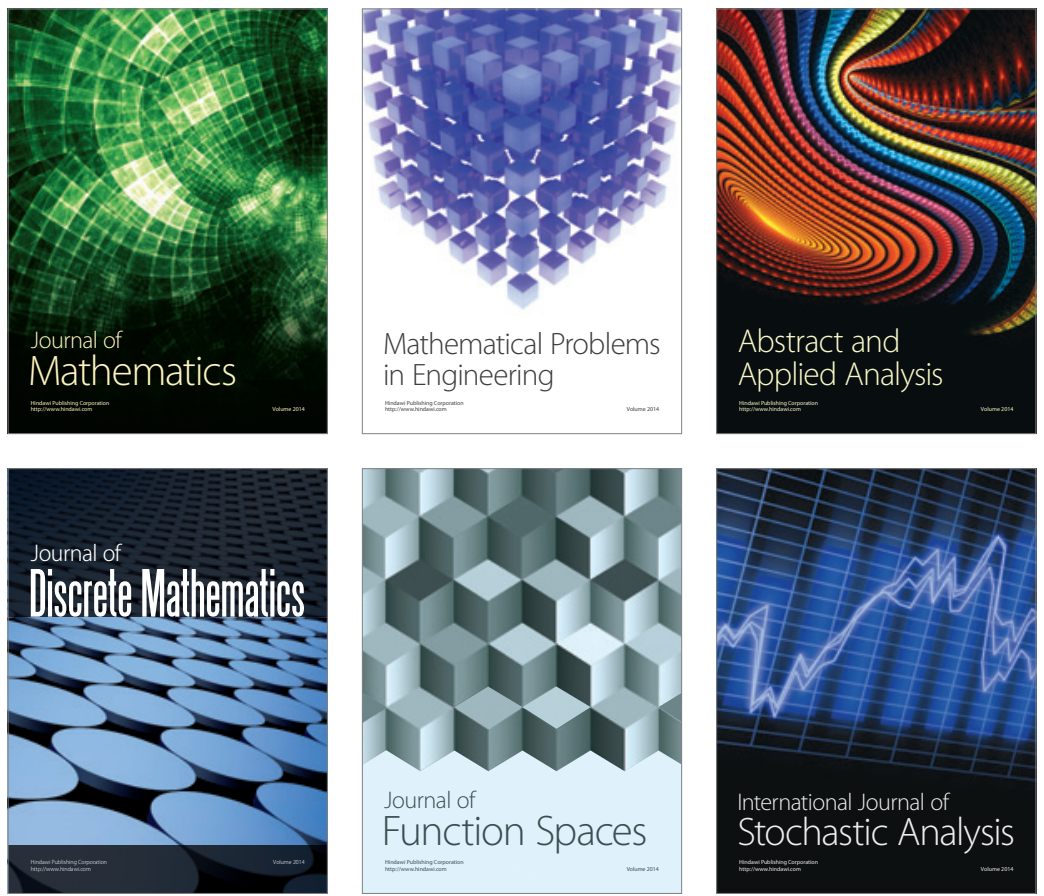

Journal of

Function Spaces

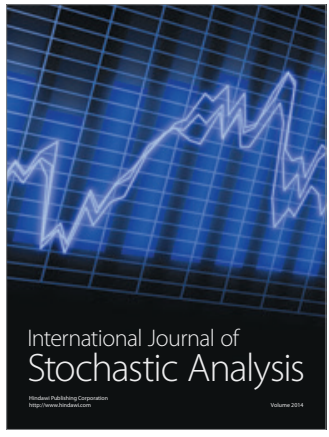

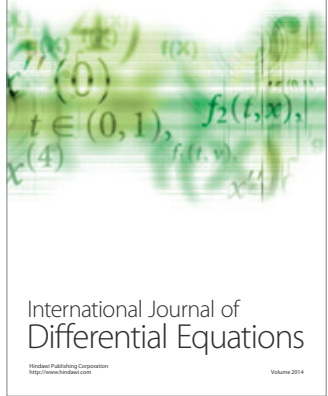
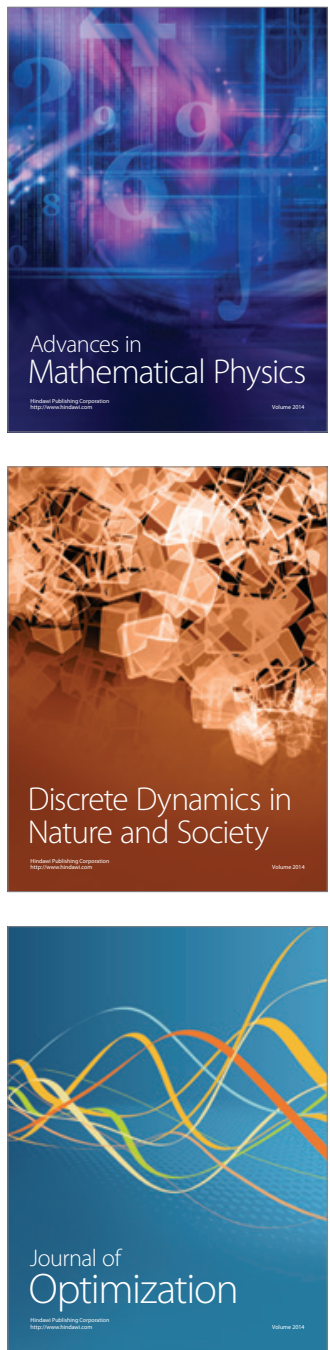